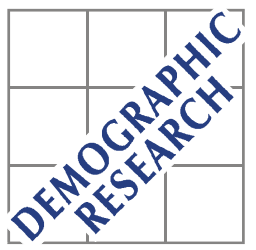

Demographic Research a free, expedited, online journal of peer-reviewed research and commentary in the population sciences published by the Max Planck Institute for Demographic Research Konrad-Zuse Str. 1, D-18057 Rostock · GERMANY www.demographic-research.org

DEMOGRAPHIC RESEARCH

VOLUME 25, ARTICLE 8, PAGES 285-310

PUBLISHED 26 JULY 2011

http://www.demographic-research.org/Volumes/Vol25/8/

DOI: $10.4054 /$ DemRes.2011.25.8

Descriptive Findings

\title{
Gender differences in social mortality differentials in Switzerland (1990-2005)
}

Reto Schumacher

Sarah Vilpert

(C) 2011 Reto Schumacher \& Sarah Vilpert.

This open-access work is published under the terms of the Creative Commons Attribution NonCommercial License 2.0 Germany, which permits use, reproduction \& distribution in any medium for non-commercial purposes, provided the original author(s) and source are given credit.

See http:// creativecommons.org/licenses/by-nc/2.0/del 


\section{Table of Contents}

1 Introduction 286

$2 \quad$ Gender differences in social mortality differentials 286

2.1 Differences in mortality by educational achievement 286

2.2 Differences in mortality by marital status 288

3 Data and methods 290

3.1 Data source 290

$\begin{array}{lll}3.2 & \text { Variable design } & 291\end{array}$

$\begin{array}{lll}3.3 & \text { Analytic strategy } & 292\end{array}$

$4 \quad$ Results 294

4.1 Gender differences in the educational mortality gradient 294

4.2 Gender differences in the mortality differential by marital status 297

$5 \quad$ Discussion and conclusion 301

$\begin{array}{lll}5.1 & \text { Data aspects } & 302\end{array}$

5.2 Summary and comparison of results 303

$\begin{array}{lll}5.3 & \text { Interpretation of results } & 305\end{array}$

$\begin{array}{lll}5.4 & \text { Conclusion } & 306\end{array}$

$\begin{array}{lll}6 & \text { Acknowledgements } & 307\end{array}$

$\begin{array}{ll}\text { References } & 308\end{array}$ 


\title{
Gender differences in social mortality differentials in Switzerland (1990-2005)
}

\author{
Reto Schumacher ${ }^{1}$ \\ Sarah Vilpert ${ }^{2}$
}

\begin{abstract}
Using data from the 1990 and 2000 Swiss Federal Censuses linked to the death records of the years 1990-1995 and 2000-2005, this paper investigates gender differences in mortality differentials by level of educational achievement and by marital status. In both periods, the differential by level of education is clearly more pronounced among men, but the difference in the educational gradient between men and women decreases between the two periods of observation. Health behavior might contribute to the gender difference in the educational mortality gradient, but it is probably not the main reason for this finding. The mortality differential by marital status is also stronger in men, but the difference between men and women narrows over time. Our analysis also shows that gender differences in the mortality differential by marital status almost disappear when gender differences in population composition by level of education, nationality, employment status, and housing situation are taken into account.
\end{abstract}

${ }^{1}$ University of Geneva, Switzerland. E-mail: reto.schumacher@unige.ch.

${ }^{2}$ Swiss Health Observatory, Switzerland. E-mail: sarah.vilpert@bfs.admin.ch. 


\section{Introduction}

Social mortality differentials have frequently been observed in past and present populations. It has been widely shown that higher socioeconomic status-regardless of whether it is measured by level of education, income, wealth, or occupation-is associated with higher longevity. It has also been shown that living with a spouse or a partner reduces the risk of mortality. Although these relationships hold for both sexes and for most age groups, social inequality in mortality is usually more pronounced among men and younger age groups. Recent studies have produced contradictory results regarding the trends in gender-specific mortality differentials by socioeconomic status. While the social gradient in mortality seems to have narrowed among Italian women (Luy, Di Giulio, and Caselli 2009), it appears to have widened among French women (Cambois and Laborde 2009).

The aim of this paper is to provide new evidence on gender differences in mortality differentials by describing recent trends in gender-specific social mortality differentials in Switzerland. Using probabilistically linked longitudinal data of the years 1990-1995 and 2000-2005, we compute life expectancies by sex and level of educational achievement, and again by sex and marital status. We also investigate whether gender differences in mortality differentials by educational level and by marital status can be explained by gender differences in population composition by nationality, employment status, and housing conditions. Finally, we compare our findings with data from the Swiss Health Surveys in order to assess the role of health behavior in explaining gender differences in social mortality differentials.

\section{Gender differences in social mortality differentials}

\subsection{Differences in mortality by educational achievement}

The association between socioeconomic status and mortality has been observed in terms of levels of education, income, wealth, or occupational position. For several reasons, demographers have mainly focused on educational achievement (Deboosere, Gadeyne, and Van Oyen 2009; Klotz and Doblhammer 2008; Rau et al. 2008; Valkonen 2002). Typical demographic sources, such as censuses and death certificates, rarely contain information on income and wealth, while occupational titles are generally only available for the working-age segment of the population. By contrast, information on completed education is usually available for retired persons as well, and can be standardized at national or international levels. Moreover, because it remains constant after a certain age in most cases, the highest completed educational level provides 
information on past, present, and future individual backgrounds. In this section, we first review explanatory factors of educational mortality differentials per se. We then ask whether these explanatory factors apply differently to men and women.

In the demographic literature, mortality differentials by educational achievement have been explained either by direct or indirect selection, or by the effects that education has on material resources and on lifestyle and health behavior (Valkonen 2002; Vallin, Caselli, and Surault 2002). Direct selection is at work when poor health deters young people from pursuing higher education, whereas indirect selection refers to factors affecting both health and education. The parents' social class, for example, may affect not only educational orientation, but also, through the transmission of a lifestyle model, risk and health behavior.

Material resources are clearly related to educational achievement. Individuals with little or no formal education often find themselves in low-income jobs, and may have to perform strenuous work. Scarce economic resources are often associated with living in unhealthy housing conditions, eating low quality food, and, depending on the institutional context, being unable to afford health care.

The higher prevalence among lower educated subgroups of risky health behaviors - such as smoking, heavy drinking, physical inactivity, and obesity-is well known, and has been shown for many countries (Klotz and Doblhammer 2008; Wray, Alwin, and McCammon 2005; Valkonen 2002; Ross and Wu 1995). Differences in lifestyle and health behavior by educational achievement have been attributed to the cognitive resources that people acquire through higher education. Ross and $\mathrm{Wu}$ (1995) have argued that, through education, people develop capacities to increase their sense of personal control, mastery, and self-direction. People with high levels of personal control are more knowledgeable about health, and are more likely to avoid unhealthy lifestyles. Vallin, Casellli, and Surault (2002) have hypothesized that there are social differences in attitudes towards the body and the self, as well as towards pain, disease, and health and medical interventions. They argue that people with lower educational levels are less able to identify the morbid nature of a given pathology and have a higher pain tolerance, and are therefore less likely to seek out medical care. Similarly, individuals with lower levels of education tend to mistrust medical science and technology more than the higher educated.

Education has also been seen as a stress reducer in the sense that cognitive skills and informal resources are helpful in handling and controlling stressful circumstances, and in conserving health capital (Deboosere, Gadeyne, and Van Oyen 2009). The capacity to cope with stress is particularly relevant because the less educated are more likely to face stressful events, such as unemployment or divorce. Differences in cognitive resources might also explain why education-related mortality differentials have been widening in the last decades. Since World War II, the population level of 
educational achievement has been rising. In other words, the proportion of people with little or no education has been steadily declining. As a result, less educated people increasingly find themselves in marginal positions, and are less likely to benefit from services (including medical care and public health campaigns) that are designed for the educated majority (Deboosere, Gadeyne, and Van Oyen 2009).

In short, differential mortality by level of educational achievement has been explained by selection, by the effect that education can have on income, and by the impact education has on cognition and health behavior. Do these explanatory factors apply differently to men and women? While there is no reason to believe that direct and indirect selection affects men and women differently, it can be hypothesized that education and material resources are less correlated among women. In older cohorts in particular, women are less involved in the labor market. The material resources of these women are therefore less dependent on their own level of educational attainment than on their husband's educational level. This might be one reason why female mortality varies less across educational levels.

The lower impact of education on women's mortality might also be due to a weaker association between education on the one hand, and lifestyle and health behavior on the other. The prevalence of harmful behaviors, such as smoking and abusive alcohol consumption, is lower among women, and is usually less subject to the social gradient than among men (Vallin 2002). In some cases, female health behavior is even subject to an inverse educational gradient. Luy, Di Giulio, and Caselli (2009) have noted that in Italy smoking has a higher prevalence among women with tertiary education. Vallin (2002) has further hypothesized that women's lifestyles remain comparatively moderate, and are shaped by what he calls a specific "culture of femininity." He has argued that, unlike men, for whom having a healthy lifestyle is dependent on the personal control achieved through higher education, women are protected by a specific perception of the body and the self, and by the habit of going to the doctor regularly.

\subsection{Differences in mortality by marital status}

In the demographic literature, different explanations as to why marital status has an influence on mortality have been advanced. In this section, we briefly review these explanatory models, and then ask whether they could apply differently to men and women.

Mortality differentials by marital status have been explained either by direct or indirect selection, or by the beneficial effects of partnership on health (Martikainen et al. 2005; Vallin, Caselli, and Surault 2002; Goldmann, Korenman, and Weinstein 1995; 
Lillard and Panis 1996; Wyke and Ford 1992; Hu and Goldmann 1990). Direct selection refers to the tendency of people with poor health to remain single (or divorced or widowed), and to the increased likelihood of divorce among married people of ill health. Indirect selection is at work when an antecedent factor affects both the probability of marriage or divorce and the risk of bad health. For example, people who engage in health-endangering behaviors, such as abusive alcohol consumption, may be less likely to find a spouse; or, if married, be subject to a higher risk of divorce (Martikainen et al. 2005).

With respect to the beneficial effects of partnership on health, it has been argued that married people benefit from greater material resources (Becker 1981), and therefore can afford healthier living conditions (such as better housing) than single, divorced, or widowed people. In particular, the positive effect of marriage on health has been interpreted in terms of lifestyle and social support. At the same ages, married people are less likely than unmarried people to use tobacco, abuse alcohol, and have road accidents; and they are more likely to obtain regular medical care (Vallin, Caselli, and Surault 2002).

Koskinen et al. (2007) have insisted on the importance of social support and stress avoidance. People who are married receive support and comfort from a partner, whereas people who live alone tend to experience stress, especially if they have not chosen to be single. Their analysis has shown that men and women of working age who live in a consensual union have higher mortality risks than married people. Koskinen and colleagues have concluded that, as a long-term commitment between spouses, marriage is even more efficient in providing support and lowering stress than a consensual union.

Differences in mortality by marital status have thus been explained by selection effects, by the material benefits marriage can provide, and by the effects of marital status on health behavior and social support. Given these explanatory factors, what could be the reasons why marital status has less impact on female mortality? Again, we do not believe that direct and indirect selection into marital status affects men and women differently. Similarly, if marriage or partnership produces higher material wellbeing, then it should be equally beneficial to both sexes. In fact, the relationship between marital status on the one hand, and health behavior and social support on the other, has been found to differ between the sexes.

Following Vallin's (2002) reasoning, it can be argued that the association between marital status and health behavior is weaker among women. If we assume that less educated women take advantage of their specific perception of the body and the self by protecting themselves against risky health behavior, then single, divorced, or widowed women would be at lower risk of health-endangering lifestyles than men living without a spouse. 
Lusyne, Page and Lievens (2001) have also pointed out that women tend to invest more heavily in supportive relationships than men. The latter are in general more likely to rely on their spouse to maintain ties with kin and close friends, and are therefore more vulnerable in case of divorce and widowhood. Kellerhals, Widmer, and Levy (2004) have found that, among Swiss couples, women invest three to four times more in intrafamilial or extrafamilial relationships than men. Furthermore, Streuli (2002) has shown that, among Swiss people who live alone, men are more likely to be socially isolated than women. Thus, not being married may be less associated with a lack of social support for women than for men.

\section{Data and methods}

\subsection{Data source}

This study uses data from the Swiss National Cohort (SNC) database. The SNC is a longitudinal research platform based on anonymous record linkage of data collected by the Swiss Federal Statistical Office (see Bopp et al. 2009; Spoerri et al. 2010), and it has already been used to study various topics, such as the association between mortality and religion (Lerch et al. 2010), or mortality differences between the language regions (Faeh et al. 2009). In order to create this longitudinal database, the 1990 and 2000 Swiss National Censuses have been linked to the death records of the years 1990-2005, as well as to the emigration records of the same period using both deterministic and probabilistic linkage.

Of course, anonymous linkage is never perfect. Potential biases in mortality estimates based on probabilistically linked data can stem from problems in the numerator and in the denominator of the mortality rate. Of the 937,637 deaths recorded between December 5, 1990 and December 31, 2005, 93.3\% could be linked to a census record. Unlinked deaths were more likely to occur among young people under age 30, foreign nationals, women, and single persons (Bopp et al. 2009). Imperfections in the denominator were mainly found among younger people. Of the individuals recorded in the 1990 census, $6.9 \%$ could be linked neither to the 2000 census, nor to an emigration or a death record. The majority of these unlinked records were for individuals aged 1029. The authors of the database (Bopp et al. 2009) have attributed the lower linkage ratio among the younger population (inducing biases in the number of person-years exposed to the risk of death) to higher mobility and urban residence in that population segment. They have also argued that younger people are more likely to live in single households, which precludes the use of information on other family members as additional linkage variables. 
For the purposes of this study, we compare two periods of identical lengths: from December 5, 1990 to December 31, 1995, and from December 5, 2000 to December 31, 2005. The censuses of December 5, 1990 and December 5, 2000 represent the starting points of two five-year follow-ups, during which individuals are followed until death, emigration, or survival at the end of the five-year period. We restrict our analysis to two five-year periods for the sake of comparability. In doing so, we also aim to minimize the potential bias in the denominator due to mobility. Individual characteristics - such as sex, age, marital status, educational achievement, employment status, nationality, and housing situation - are drawn from the censuses, and are supposed to be constant during the time of follow-up. Unfortunately, our data do not allow us to identify changes in the potentially time-varying variables, such as marital status or labor force participation. Age is therefore the only time-varying covariate.

\subsection{Variable design}

The variable 'educational achievement' builds on information on the highest achieved level of formal education. In the Swiss educational system, compulsory schooling lasts nine years, and usually consists of six years of primary school and three years of firstlevel secondary school. Individuals with primary and first-level secondary schooling or less have been grouped into the category 'primary education'. After completion of their compulsory schooling, Swiss students usually opt for an apprenticeship, enroll in a vocational training school (both 3-4 years), or go to a school that prepares them for tertiary education. People with completed level-two secondary education have been grouped into the category 'secondary education'. Individuals with a completed university degree obtained from a university or a university of applied sciences, as well as people with advanced vocational training, have been grouped into the category 'tertiary education'. The first category corresponds to nine years of schooling or less, whereas the second and the third categories correspond to 12-13 and 15+ years of education, respectively. A descriptive analysis of the distribution of observed personyears by sex, age, and educational achievement shows that, during both periods of observation and in all age groups, the proportion of graduates of tertiary education is higher among men than among women. It also shows a steady increase in the population's level of education across time and cohorts. The information on educational achievement is missing in 3\% of all individuals aged 30 and older in the 1990 census, and in $8 \%$ in the 2000 census. In the multivariate analyses (see Sections 4.1 and 4.2), cases with missing information are treated as a distinct educational category.

The variable 'marital status' combines information drawn from questions on household composition with information on civil status. Aside from the four civil 
statuses (single, married, divorced, widowed) it further distinguishes non-married cohabiting couples. The analysis of the distribution of observed person-years by period of follow-up, sex, age, and marital status shows that the number of non-married cohabiting couples is important among younger adults, but is relatively small in the age group $70+$. The marital status is reported for all individuals in both censuses.

\subsection{Analytic strategy}

In order to address the question of gender differences in mortality differentials by educational achievement and by marital status, we first compute life expectancies by sex and level of education, and by sex and marital status, respectively. We consider life expectancy an easily interpretable indicator that policy makers are very likely to look at. The computation of the life expectancies relies on abridged (five-year) life tables. The mean numbers of person-years per age interval lived by individuals dying in that interval $\left(n_{\mathrm{X}}\right)$, which are necessary to convert age-specific mortality rates $\left(\mathrm{n}_{\mathrm{X}}\right)$ into probabilities of dying $\left(n q_{X}\right)$, have been determined empirically from our data for each sex and for each period of follow-up. The standard errors of the life expectancies are computed according to Chiang (1984).

While between-group differences in life expectancy are easily interpretable, the extent of these differences in absolute and relative terms depends on the underlying level of mortality. Gender differences in the educational mortality gradient measured in terms of life expectancy, for example, will also depend on mortality differences between the sexes. Differences in mortality rate ratios do not depend on group-specific mortality levels. Moreover, age-specific rate ratios better reveal the age pattern of a given mortality differential than a single measure of life expectancy. In a second step, we therefore look at the age patterns of selected mortality differentials with a marked gender-specific outcome by comparing age-specific mortality rate ratios.

In order to assess the dependency of these rate ratios on the population composition by a series of control variables, we run Poisson regression models for each five-year age group, including an interaction term between sex and the variable of interest (either educational achievement or marital status), and controlling for marital status or education (depending on the variable of interest), nationality, employment status, and housing conditions.

There are various reasons why we chose to control for these socio-demographic variables. First, these factors are typically available in censuses and have been used in comparable studies on social mortality differentials (Koskinen et al. 2007; Lerch et al. 2010; Martikainen et al. 2005). 'Nationality' is a binary factor distinguishing Swiss citizens from foreign nationals that allows us to control for the healthy migrant effect; 
i.e., the lower mortality among immigrants (Razum, Zeeb, and Rohrmann 2000). Martikainen et al. (2005) have shown that controlling for individuals' employment status reduces the mortality differential between the married and the never-married population in both sexes. In our study, we can distinguish between the economically active population, the unemployed, and the economically inactive population. Unemployed individuals differ from the economically inactive in that they are actively looking for work on the job market, and benefit from unemployment insurance. A model that analyzes mortality differentials by level of education should also control for income in order to assess whether the educational gradient is related to material resources. Since the Swiss censuses do not report information on income or wealth, we also include information on individuals' housing conditions. We can distinguish individuals living in a dwelling owned by a household member from individuals living in a rented apartment. Among the latter, we can further distinguish between low-priced and high-priced apartments, as the censuses report the monthly rents. We consider an apartment to be high priced if the rent is greater than the canton-and-size-specific third quartile, with size being measured in terms of number of rooms. This rather crude proxy for income and wealth therefore has three categories: namely, owners, renters of an expensive rental apartment, and renters of a cheaper tenement.

In a last step, we compute life expectancies adjusted for gender differences in population composition by marital status (or level of education), and the four confounding variables. The life table functions rely on comparative mortality rates (Chiang 1984) obtained by multiple direct standardization. In most demographic textbooks, the rationale of direct standardization is illustrated by the example of ageadjusted death rates (Preston, Heuvline, and Guillot 2001; McGehee 2004). In order to compute comparable death rates for two populations with different age compositions, we can weight the two age-specific rate schedules by a common age distribution. The technique of direct standardization also applies to adjustments other than for age, and can involve more than one factor. In the present case, we adjust observed mortality rates by sex, age, and educational level (or marital status) for gender differences in marital status (or educational achievement), nationality, employment status, and housing situation. A given mortality rate by age, sex, and level of education-e.g., the rate of men aged 50 to 54 with secondary education - can be thought of as the weighted average of $5 \cdot 2 \cdot 3 \cdot 3=90$ rates by marital status (five categories), nationality (two categories), employment status (three categories), and housing situation (three categories). As the proportional distribution of person-years by these four control factors differs between the sexes, the 90 rates in each age group of both sexes are weighted by the gender-averaged distribution. The resulting comparative mortality rates assume equal proportional composition among men and women by marital status, nationality, employment status, and housing situation. 


\section{Results}

\subsection{Gender differences in the educational mortality gradient}

Table 1 reports the life expectancy at age 30 (e30) and age 65 (e65) by sex, level of educational achievement, and period of follow-up. While e30 is determined by the cumulative effects of mortality during adulthood and old age, e 65 essentially reflects the effects of old age mortality. The standard errors given in the second position can be used to assess the significance of the difference between two life expectancies. Twice the standard error gives approximately half of a $95 \%$ confidence interval. In the third position, the absolute difference in longevity compared to the lowest educational category is reported.

Table 1: Life expectancy by sex and level of education; Switzerland 1990-95 and 2000-05

\begin{tabular}{|c|c|c|c|c|c|c|c|c|c|c|c|c|}
\hline \multirow[b]{2}{*}{$1990-95$} & \multicolumn{3}{|c|}{ men } & \multicolumn{3}{|c|}{ women } & \multicolumn{3}{|c|}{ men } & \multicolumn{3}{|c|}{ women } \\
\hline & $\mathbf{e}_{30}$ & $\sigma_{\mathrm{e} 30}$ & $\Delta$ & $\mathbf{e}_{30}$ & $\sigma_{\mathrm{e} 30}$ & $\Delta$ & $\mathbf{e}_{65}$ & $\sigma_{\mathrm{e} 65}$ & $\Delta$ & $\mathbf{e}_{65}$ & $\sigma_{\mathrm{e} 65}$ & $\Delta$ \\
\hline primary & 45.2 & 0.06 & & 52.4 & 0.04 & & 15.2 & 0.04 & & 20.2 & 0.03 & \\
\hline secondary & 47.1 & 0.04 & 1.9 & 54.0 & 0.05 & 1.6 & 16.4 & 0.03 & 1.2 & 21.5 & 0.04 & 1.3 \\
\hline \multirow[t]{2}{*}{ tertiary } & 49.7 & 0.07 & 4.5 & 55.2 & 0.15 & 2.8 & 17.9 & 0.06 & 2.7 & 22.4 & 0.14 & 2.2 \\
\hline & \multicolumn{3}{|c|}{ men } & \multicolumn{3}{|c|}{ women } & \multicolumn{3}{|c|}{ men } & \multicolumn{3}{|c|}{ women } \\
\hline $2000-05$ & $\mathbf{e}_{30}$ & $\sigma_{\mathrm{e} 30}$ & $\Delta$ & $\mathbf{e}_{30}$ & $\sigma_{\mathrm{e} 30}$ & $\Delta$ & $\mathbf{e}_{65}$ & $\sigma_{\mathrm{e} 65}$ & $\Delta$ & $\mathbf{e}_{65}$ & $\sigma_{\mathrm{e} 65}$ & $\Delta$ \\
\hline primary & 47.9 & 0.06 & & 53.8 & 0.04 & & 16.9 & 0.04 & & 21.2 & 0.03 & \\
\hline secondary & 50.1 & 0.04 & 2.2 & 55.4 & 0.04 & 1.6 & 18.4 & 0.04 & 1.5 & 22.3 & 0.04 & 1.1 \\
\hline tertiary & 53.0 & 0.06 & 5.1 & 56.9 & 0.12 & 3.1 & 20.1 & 0.06 & 3.2 & 23.6 & 0.11 & 2.4 \\
\hline
\end{tabular}

Our analysis shows a clear educational gradient in both male and female longevity. As expected, the association between education and mortality is clearly stronger among men. At age 30, men with tertiary education live, on average, 4.5 to five years, or $10 \%$ longer than men with only primary education. Among women, the gain in longevity associated with having a tertiary degree is about three years in absolute terms, or about $5 \%$ in relative terms. It is also shown that, among men, the difference between secondary and tertiary education is greater than the differential between the primary and secondary levels; whereas among women, the distance is greater between the two lower 
levels. Educational achievement also has different effects on male and female mortality during old age. At age 65, the absolute educational differentials in longevity have diminished in both sexes, and the gender differences in the educational gradient have become smaller. Nonetheless, men with tertiary education live about three years, or over $18 \%$, longer than men with primary education. Among women, the difference in longevity after age 65 between the primary and tertiary levels is about 2.3 years, or $11 \%$. The comparison of the two periods of follow-up indicates an increase of the gradient in both men and women. In relative terms, however, the educational differentials in longevity remain almost constant over time among both sexes.

Figure 1a gives more detailed information on the age patterns of the mortality differential between tertiary and primary education in both sexes. It can easily be seen that, among men, the differential decreases almost linearly with age (that is, the mortality rate ratio increases steadily to approach equality towards the end of the life span); whereas among women, the mortality rate ratio remains more or less constant, at least after age 45. Hence, the stronger educational mortality gradient among men reported by Table 1 results mainly from a more pronounced differential between men with primary education and men with tertiary education in the middle age groups. After age 75 , there are no clear gender differences in the association between education and mortality.

Figure $1 \mathrm{~b}$ shows the same mortality rate ratios adjusted for the main effects of marital status, nationality, employment status, and housing conditions in a multivariate regression model. Controlling for the population composition by these four variables shows that none substantially affects the level or the age patterns of men's and women's educational mortality gradients. Among men, the decrease of the analyzed differential with age becomes slightly more linear, while among women, there is a little more age dependency in the mortality rate ratios. 
Figure 1a: Mortality rate ratios (tertiary vs. primary education) by sex
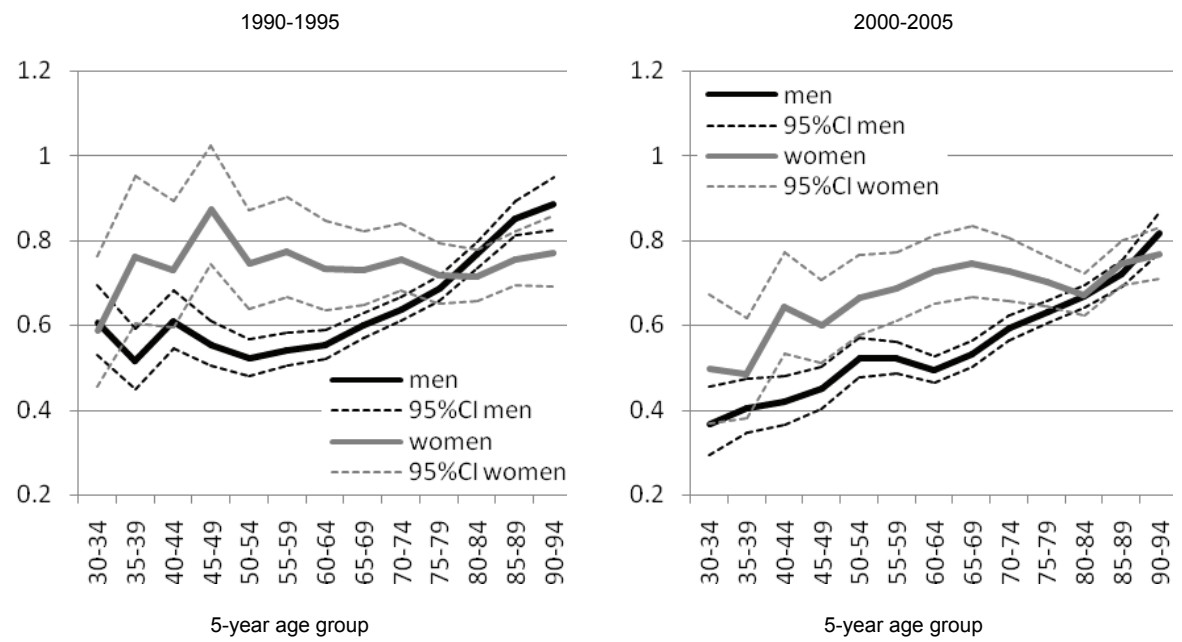

Figure 1b: Mortality rate ratios (tertiary vs. primary education) by sex, adjusted for gender differences in population composition by marital status, nationality, employment status, and housing situation.

1990-1995

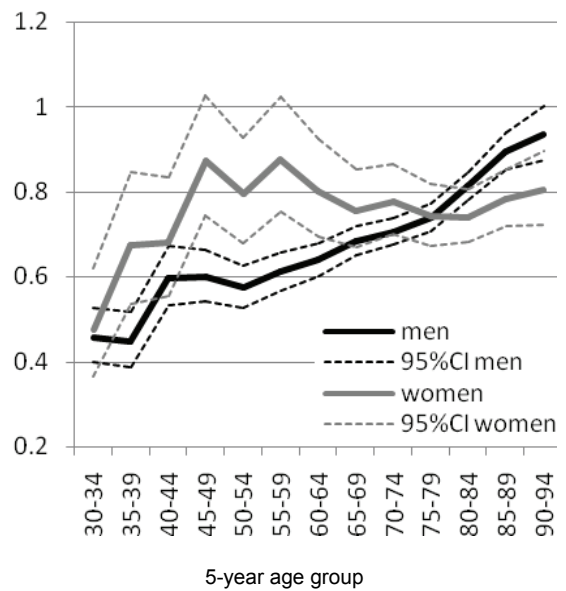

2000-2005

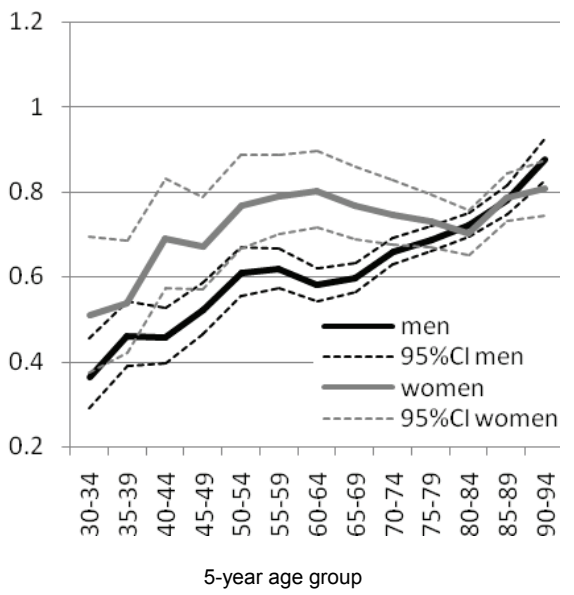


Table 2 reports life expectancies by sex and level of educational achievement, adjusted for gender differences in the population composition by marital status, nationality, employment status, and housing conditions. Given the results of Figure 1b, it is not surprising to observe only minor changes in the gender difference of the association between mortality and education. Among men, the educational gradient turns out to be a little stronger during the first period of follow-up when gender differences in population composition are accounted for. The opposite can be observed among women, with the gradient increasing slightly between the first and the second period of observation. As a result, absolute and relative gender differences in the educational mortality gradient grow smaller between 1990-1995 and 2000-2005.

Table 2: Life expectancy by sex and level of education, adjusted for gender differences in population composition by marital status, nationality, employment status, and housing situation; Switzerland 1990-95 and 2000-05

\begin{tabular}{|c|c|c|c|c|c|c|c|c|c|c|c|c|}
\hline \multirow[b]{2}{*}{$1990-95$} & \multicolumn{3}{|c|}{ men } & \multicolumn{3}{|c|}{ women } & \multicolumn{3}{|c|}{ men } & \multicolumn{3}{|c|}{ women } \\
\hline & $\mathbf{e}_{30}$ & $\sigma_{\mathrm{e} 30}$ & $\Delta$ & $\mathbf{e}_{30}$ & $\sigma_{\mathrm{e} 30}$ & $\Delta$ & $e_{65}$ & $\sigma_{\mathrm{e} 65}$ & $\Delta$ & $e_{65}$ & $\sigma_{\mathrm{e} 65}$ & $\Delta$ \\
\hline primary & 42.5 & 0.07 & & 52.9 & 0.04 & & 14.7 & 0.04 & & 20.4 & 0.03 & \\
\hline secondary & 45.1 & 0.05 & 2.6 & 54.4 & 0.04 & 1.5 & 16.0 & 0.03 & 1.3 & 21.7 & 0.04 & 1.3 \\
\hline \multirow[t]{2}{*}{ tertiary } & 48.2 & 0.07 & 5.7 & 55.4 & 0.04 & 2.5 & 17.3 & 0.06 & 2.6 & 22.4 & 0.13 & 2.0 \\
\hline & \multicolumn{3}{|c|}{ men } & \multicolumn{3}{|c|}{ women } & \multicolumn{3}{|c|}{ men } & \multicolumn{3}{|c|}{ women } \\
\hline $2000-05$ & $\mathbf{e}_{30}$ & $\sigma_{\mathrm{e} 30}$ & $\Delta$ & $\mathbf{e}_{30}$ & $\sigma_{\mathrm{e} 30}$ & $\Delta$ & $\mathbf{e}_{65}$ & $\sigma_{\mathrm{e} 65}$ & $\Delta$ & $\mathbf{e}_{65}$ & $\sigma_{\mathrm{e} 65}$ & $\Delta$ \\
\hline primary & 46.8 & 0.06 & & 54.2 & 0.04 & & 16.4 & 0.04 & & 21.6 & 0.03 & \\
\hline secondary & 48.8 & 0.05 & 2.0 & 55.9 & 0.04 & 1.7 & 18.0 & 0.04 & 1.6 & 22.7 & 0.04 & 1.1 \\
\hline tertiary & 52.0 & 0.06 & 5.2 & 57.7 & 0.12 & 3.5 & 19.7 & 0.06 & 3.3 & 24.3 & 0.12 & 2.7 \\
\hline
\end{tabular}

\subsection{Gender differences in the mortality differential by marital status}

Table 3 reports life expectancies at age 30 and at age 65 by sex, marital status, and period of follow-up. The interpretation of life expectancies by marital status is less straightforward than the previously discussed measures of longevity by educational achievement. While the level of education can be thought of as a fixed characteristic after a certain age (e.g., age 30 ) the marital status is a potentially time-varying variable. 
The life expectancies reported in Table 3 do not account for such changes over time. They refer instead to (hypothetical) individuals who do not change their marital status after age 30 and after age 65 , respectively. It should also be noted that, particularly in lower age groups, certain marital categories are small in number. As a consequence, the standard errors of the probabilities of dying are high, and so are the margins of error of life expectancies.

Table 3: $\quad$ Life expectancy by sex and marital status; Switzerland 1990-95 and 2000-05

\begin{tabular}{|c|c|c|c|c|c|c|c|c|c|c|c|c|}
\hline \multirow[b]{2}{*}{$1990-95$} & \multicolumn{3}{|c|}{ men } & \multicolumn{3}{|c|}{ women } & \multicolumn{3}{|c|}{ men } & \multicolumn{3}{|c|}{ women } \\
\hline & $\mathbf{e}_{30}$ & $\sigma_{\mathrm{e} 30}$ & $\Delta$ & $\mathbf{e}_{30}$ & $\sigma_{\mathrm{e} 30}$ & $\Delta$ & $\mathbf{e}_{65}$ & $\sigma_{\mathrm{e} 65}$ & $\Delta$ & $\mathbf{e}_{65}$ & $\sigma_{\mathrm{e} 65}$ & $\Delta$ \\
\hline single & 42.4 & 0.10 & & 51.7 & 0.09 & & 14.6 & 0.08 & & 20.2 & 0.06 & \\
\hline divorced & 43.5 & 0.48 & 1.1 & 51.8 & 0.24 & 0.1 & 14.7 & 0.09 & 0.1 & 20.4 & 0.04 & 0.2 \\
\hline widowed & 42.2 & 0.16 & 0.2 & 51.1 & 0.13 & 0.6 & 14.4 & 0.13 & -0.2 & 19.9 & 0.1 & -0.3 \\
\hline cohabiting & 46.2 & 0.20 & 3.8 & 53.4 & 0.28 & 1.7 & 16.1 & 0.20 & 1.5 & 21.4 & 0.28 & 1.2 \\
\hline \multirow[t]{2}{*}{ married } & 48.2 & 0.03 & 5.8 & 54.0 & 0.05 & 2.3 & 16.7 & 0.03 & 2.1 & 21.3 & 0.04 & 1.1 \\
\hline & \multicolumn{3}{|c|}{ men } & \multicolumn{3}{|c|}{ women } & \multicolumn{3}{|c|}{ men } & \multicolumn{3}{|c|}{ women } \\
\hline $2000-05$ & $\mathbf{e}_{30}$ & $\sigma_{\mathrm{e} 30}$ & $\Delta$ & $\mathbf{e}_{30}$ & $\sigma_{\mathrm{e} 30}$ & $\Delta$ & $\mathbf{e}_{65}$ & $\sigma_{\mathrm{e} 65}$ & $\Delta$ & $\mathbf{e}_{65}$ & $\sigma_{\mathrm{e} 65}$ & $\Delta$ \\
\hline single & 45.1 & 0.10 & & 52.3 & 0.09 & & 15.4 & 0.09 & & 20.6 & 0.07 & \\
\hline divorced & 46.4 & 0.48 & 1.3 & 52.7 & 0.27 & 0.4 & 16.2 & 0.09 & 0.8 & 21.0 & 0.04 & 0.4 \\
\hline widowed & 45.9 & 0.13 & 0.8 & 52.7 & 0.10 & 0.4 & 15.9 & 0.11 & 0.5 & 20.6 & 0.08 & 0.0 \\
\hline cohabiting & 49.8 & 0.15 & 4.7 & 54.6 & 0.17 & 2.3 & 18.1 & 0.15 & 2.7 & 21.9 & 0.17 & 1.3 \\
\hline married & 51.1 & 0.03 & 6.0 & 56.3 & 0.04 & 4.0 & 18.7 & 0.03 & 3.3 & 23.1 & 0.04 & 2.5 \\
\hline
\end{tabular}

The results show that, in both sexes, the mortality differential by marital status essentially indicates that, when individuals who live alone (the single, divorced, and widowed) are compared to men or women who live with a spouse or a partner, the latter clearly live longer. While there is no clear difference in longevity between the first three marital categories, there is a significant difference between married and cohabiting individuals. Among both men and women, marriage seems to be more efficient than cohabitation in keeping people healthy. However, the mortality differential between individuals who live alone and individuals who cohabit with a spouse or a partner is more pronounced among men than among women. In both 
periods of follow-up, the difference in longevity between a man who remains single after age 30 and a man who remains married is about six years in absolute terms, or about $13 \%$ in relative terms. Among women, this difference is 2.3 years (or $4.5 \%$ ) in 1990-1995, and reaches four years (or 7.5\%) in 2000-2005. The differential thus becomes more important among women. As a result, the gender difference in the mortality differential by marital status narrows between the two periods of follow-up. At age 65, the difference in longevity between married and single men increases from 2.1 years in 1990-1995 to 3.3 years in 2000-2005, whereas among women that differential rises from 1.1 to 2.5 years. This sharper increase in women explains the narrowing gender gap in the old age mortality differential by marital status.

Figure 2a presents the age patterns of the mortality differential between single and married individuals. In both sexes, the differential is clearly age dependent. The reduction in mortality induced by marriage decreases almost linearly with age, and becomes non-significant at the end of the life span. The gender difference in this particular mortality differential is most pronounced in younger and middle aged groups, among whom marriage has a greater impact on male mortality. After age 75, marriage affects male mortality to the same extent as female mortality. As has already been pointed out in Table 3, the gender difference in the married-single differential is much weaker in the second period of follow-up.

Figure $2 \mathrm{~b}$ shows adjusted mortality rate ratios between married and single men and women, respectively. The mortality rates by age, sex, and marital status upon which the rate ratios are based have been adjusted for gender differences in population composition by levels of educational achievement, nationality, employment status, and housing conditions. The comparison between Figures $2 \mathrm{a}$ and $2 \mathrm{~b}$ clearly shows that, when differences in population composition are taken into account, marriage affects male and female mortality more or less equally. During the second period of follow-up, the differential even turns out to be slightly stronger among women. A closer look at the analyses shows that the married-single mortality differential in women is insensitive to the main effects of education, nationality, and housing conditions, but reacts to the inclusion of the employment status. Once gender differences in the distribution by employment status are taken into account, marriage reduces women's mortality to the same extent as men's mortality. Or, put differently, singlehood increases women's mortality as much as men's mortality when combined with economic inactivity. 
Figure 2a: Mortality rate ratios (married vs. single) by sex
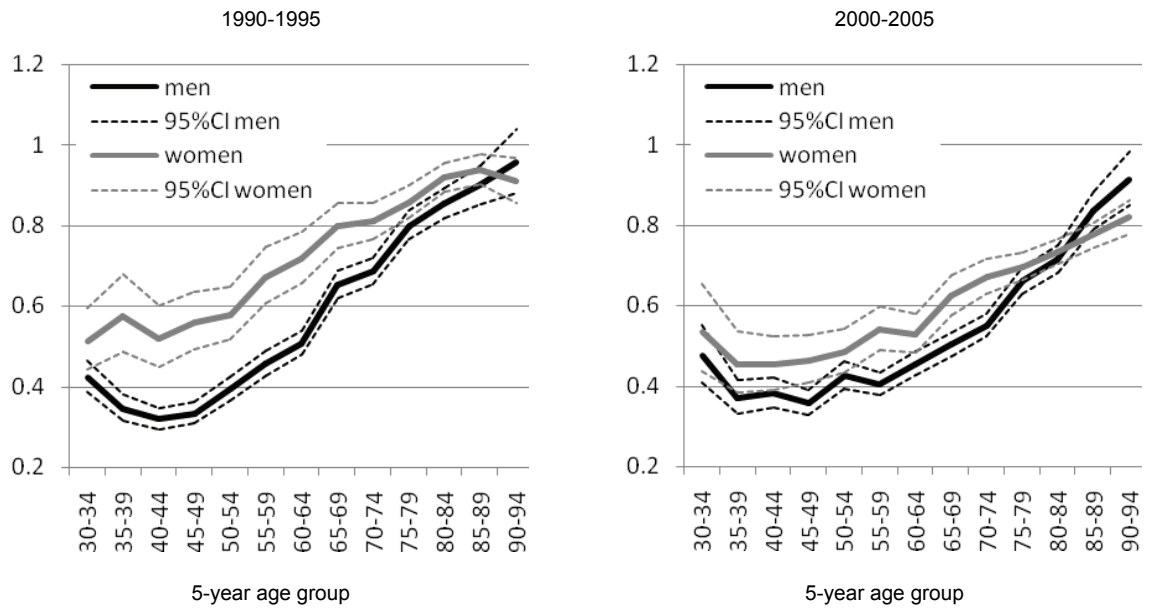

Figure 2b: Mortality rate ratios (married vs. single) by sex, adjusted for gender differences in population composition by educational achievement, nationality, employment status, and housing situation.
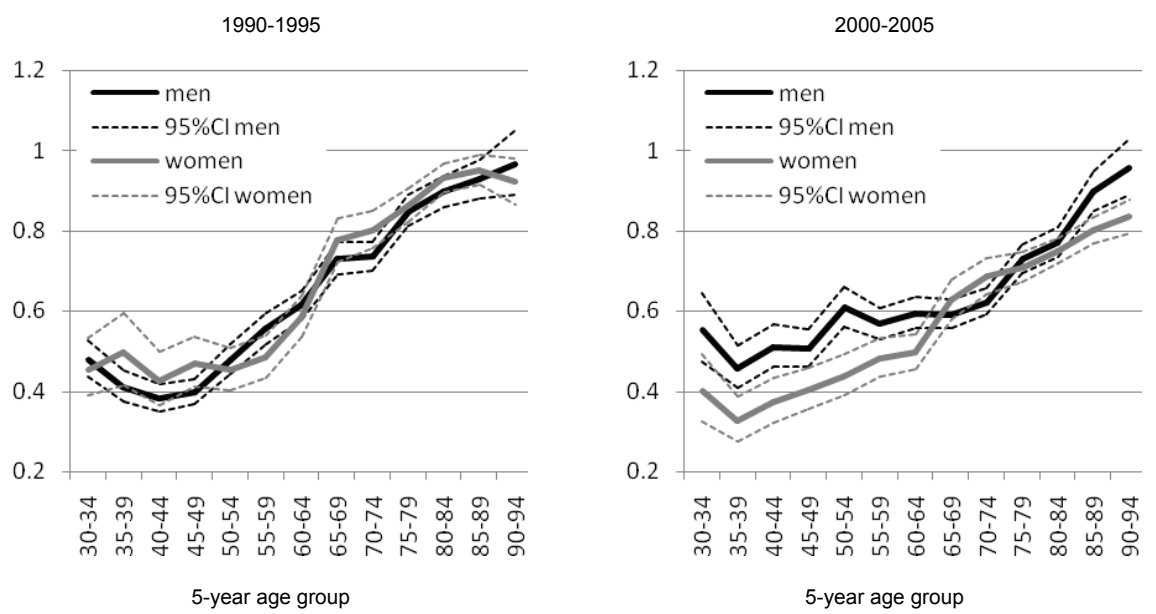
Table 4 reports life expectancies by sex and marital status adjusted for gender differences in the population composition by educational achievement, nationality, employment status, and housing condition. When life expectancies are computed using multiple standardized mortality rates, the gender differences in the differential by marital status narrow substantially. Differences in population composition-i.e., differences in the joint distribution by employment status and marital status - therefore explain to a large extent the gender differences in the mortality differential by marital status.

Table 4: $\quad$ Life expectancy by sex and marital status, adjusted for gender differences in population composition by educational achievement, nationality, employment status, and housing situation. Switzerland 1990-95 and 2000-05

\begin{tabular}{|c|c|c|c|c|c|c|c|c|c|c|c|c|}
\hline \multirow[b]{2}{*}{$1990-95$} & \multicolumn{3}{|c|}{ men } & \multicolumn{3}{|c|}{ women } & \multicolumn{3}{|c|}{ men } & \multicolumn{3}{|c|}{ women } \\
\hline & $\mathbf{e}_{30}$ & $\sigma_{\mathrm{e} 30}$ & $\Delta$ & $\mathbf{e}_{30}$ & $\sigma_{\mathrm{e} 30}$ & $\Delta$ & $\mathbf{e}_{65}$ & $\sigma_{\mathrm{e} 65}$ & $\Delta$ & $\mathbf{e}_{65}$ & $\sigma_{\mathrm{e} 65}$ & $\Delta$ \\
\hline single & 42.0 & 0.10 & & 51.9 & 0.09 & & 14.4 & 0.08 & & 20.3 & 0.06 & \\
\hline divorced & 39.3 & 0.96 & 2.7 & 52.6 & 0.19 & 0.7 & 14.2 & 0.09 & -0.2 & 20.7 & 0.04 & 0.4 \\
\hline widowed & 40.9 & 0.17 & 1.1 & 51.7 & 0.12 & 0.2 & 13.9 & 0.13 & -0.5 & 20.2 & 0.10 & -0.1 \\
\hline cohabiting & 44.8 & 0.21 & 2.8 & 53.6 & 0.26 & 1.7 & 15.7 & 0.20 & 1.3 & 21.4 & 0.26 & 1.1 \\
\hline \multirow[t]{2}{*}{ married } & 45.4 & 0.04 & 3.4 & 54.5 & 0.05 & 2.6 & 16.3 & 0.03 & 1.9 & 21.6 & 0.04 & 1.3 \\
\hline & \multicolumn{3}{|c|}{ men } & \multicolumn{3}{|c|}{ women } & \multicolumn{3}{|c|}{ men } & \multicolumn{3}{|c|}{ women } \\
\hline 2000-05 & $\mathbf{e}_{30}$ & $\sigma_{\mathrm{e} 30}$ & $\Delta$ & $\mathbf{e}_{30}$ & $\sigma_{\mathrm{e} 30}$ & $\Delta$ & $\mathbf{e}_{65}$ & $\sigma_{\mathrm{e} 65}$ & $\Delta$ & $\mathbf{e}_{65}$ & $\sigma_{\mathrm{e} 65}$ & $\Delta$ \\
\hline single & 44.9 & 0.10 & & 52.3 & 0.09 & & 15.2 & 0.09 & & 20.6 & 0.07 & \\
\hline divorced & 44.9 & 0.53 & 0 & 53.4 & 0.20 & 1.1 & 15.7 & 0.10 & 0.5 & 21.3 & 0.04 & 0.7 \\
\hline widowed & 45.1 & 0.13 & 0.2 & 53.3 & 0.10 & 1.0 & 15.3 & 0.11 & 0.1 & 21.0 & 0.08 & 0.4 \\
\hline cohabiting & 49.0 & 0.16 & 4.1 & 55.0 & 0.17 & 2.7 & 17.7 & 0.15 & 2.5 & 22.1 & 0.16 & 1.5 \\
\hline married & 49.6 & 0.04 & 4.7 & 56.7 & 0.05 & 4.4 & 18.3 & 0.03 & 3.1 & 23.4 & 0.04 & 2.8 \\
\hline
\end{tabular}

\section{Discussion and conclusion}

The aim of this paper is to analyze gender differences in mortality differentials by level of educational achievement and by marital status in Switzerland between 1990-1995 and 2000-2005. Our analysis is based on longitudinal data obtained from a deterministic and probabilistic record linkage of the Swiss Federal Censuses of the years 1990 and 
2000 to the death records of the years 1990-1995 and 2000-2005, respectively. To address the specific question of gender differences in social mortality differentials, we have computed life expectancies at age 30 and at age 65 by sex and level of education, and by sex and marital status. The age patterns of these gender-specific differentials and their dependence on population composition by nationality, employment status, and housing situation have been analyzed through Poisson regression analysis. Finally, we have computed life expectancies adjusted for gender differences in population composition by these confounding factors.

\subsection{Data aspects}

As they were obtained from anonymous record linkage, the data we use have limitations, and the effects of these limitations on our results must be discussed. First, the problem of unlinked deaths potentially biases the numerator of the mortality rate, and may lead to an underestimation of its true value. The proportion of unlinked deaths has been found to be above average among younger ages at death, foreign nationals, and the female and single populations (Bopp et al. 2009). Since we restrict our analysis to the population aged 30 and older, the higher proportion among younger ages at death should not affect our results. Meanwhile, the lower linkage ratio of death certificates in the foreign population almost certainly stems from immigrants who took up residence in Switzerland after 1990, and then after 2000. As these individuals had not been recorded in the censuses, they are not part of the risk population. Therefore, the mortality rate of the foreign nationals included in the risk population should not be biased. The higher proportion of unlinked deaths in the female population is unlikely to affect gender differences in the mortality differentials by educational achievement and by marital status. However, it may cause an overestimation of the overall mortality difference between men and women. More problematic is the higher number of unlinked deaths in the single population. Again, it should not bias the extent to which the analyzed mortality differentials differ by gender, but it may lead to an underestimation of the mortality differences between the ever-married and the nevermarried populations.

Second, the problem of unlinked individuals (that is, individuals who cannot be linked to the next census, a death certificate, or an emigration record) can lead to an overestimation of the denominator of the mortality rate. As this problem is found mainly in the population aged 10-29, and since we restricted the first follow-up period to five years, the impact of this imperfection on our results should be negligible.

Finally, we have to deal with missing values in the level of educational achievement. Although the category of unknown educational level is small, it is 
possible to compute life expectancies for both sexes. Except for the male population in the period 2000-2005, the obtained values are very close to the values computed for the category of primary education. We may conclude from this result that individuals without a known level of education mostly have a primary degree (compulsory schooling or less). Their inclusion in the category of primary education would not alter our results, but it would lower the standard errors of the life expectancies estimated for that category. The life expectancies we computed for men with an unknown level of education in the period 2000-2005 are significantly lower than those we found for men with primary education. Again, we may conclude from this result that most of the men whose educational level is unknown have earned a primary degree. Their inclusion in that category would lower the life expectancies we found for men with primary education. However, with a change of 0.2 years in e 30 , the effect is small.

\subsection{Summary and comparison of results}

The results of our analyses confirm the greater degree of social inequality in male than in female mortality. The educational gradient in Swiss mortality has been found to be much stronger among men. At age 30, men with tertiary education can expect to live 4.5 to five years longer than men with primary education, while among women, this difference is only about three years. The comparison of the two periods of follow-up has shown no clear evolution in the gender difference of the educational mortality differential, at least when unadjusted life expectancies are considered.

Our analysis of age-sex-specific mortality rate ratios has shown that the stronger educational gradient among Swiss men arises from more pronounced educational differences in younger and middle age groups, with the rate ratios being less agedependent among women.

The multivariate analysis controlling for gender differences in the population composition by marital status, nationality, employment status, and housing conditions has shown only minor effects of population composition on the gender difference in the educational mortality gradient. However, when life expectancies are adjusted for population composition by these four confounding variables, we find a decrease over time in the gender difference in the educational mortality gradient. The multivariate analysis has also stressed the gradient's independence from housing conditions, a variable we used as a proxy for income and wealth. In fact, the inclusion of the variable housing situation in the models predicting numbers of deaths does not alter the main effect of the variable 'level of educational achievement'. This result highlights that, in Switzerland, mortality differentials by level of education do not seem to be related to people's financial capital. 
The gender difference in the educational mortality gradient we find for Switzerland is comparable to the gaps that have been identified in other European countries. The difference is slightly less pronounced than in Austria, where in 20012002 men and women aged 35 years with tertiary education could expect to live six and three years longer, respectively, than individuals with primary education (Klotz and Doblhammer 2008). The gap turns out to be larger than in Belgium, where in 2001 the same differentials at age 25 were 7.5 years for men and 5.9 years for women (Deboosere, Gadeyne, and Van Oyen 2009).

In both sexes, the mortality differential by marital status essentially compares individuals who live alone with people who live with a spouse or a partner. However, the difference between the single, divorced, and widowed on the one hand; and married or cohabiting individuals on the other; is more pronounced among men. At age 30, married men can expect to live six years longer than men who remain single, whereas among women, this differential amounts to 2.3 to four years. Because the mortality differential by marital status grows stronger among women between 1990-95 and 200005 , the gender gap in this differential is decreasing.

However, the multivariate analysis has shown that gender differences in population composition have an important impact on the gender difference in this mortality differential. When age-specific mortality rates are standardized by the genderaveraged composition by level of education, nationality, employment status, and housing situation, gender differences in the way marital status affects mortality become small. This result is interesting. It indicates that differences between the sexes in this mortality differential are not solely related to marital status itself, but also to factors correlated with gender and marital status.

When compared to other countries, the gender gap in the Swiss mortality differential by marital status turns out to be higher than average. In an international comparison of 16 industrialized countries, Hu and Goldmann (1990) have found an average excess mortality of nearly $100 \%$ among non-married working-age men, compared to an average excess of about $50 \%$ among single, divorced, and widowed women of the same age. Martikainen et al. (2005) have found similar results for Finland when the rate ratios were adjusted for population composition by socioeconomic status and economic activity. Our analysis has shown that excess mortality of the nevermarried population compared to the married population is about $150 \%$ in working-age men, and between $66 \%$ and $100 \%$ in working-age women. 


\subsection{Interpretation of results}

In the literature, it has been hypothesized that the weaker educational gradient in female mortality could be due to a looser relationship between material resources and educational attainment among women, or to a looser association between cognitive resources and lifestyle. Similarly, more homogenous health behaviors among women (Vallin 2002) might explain why marital status affects female mortality to a lesser extent. Lusyne, Page, and Lievens (2005) have argued that men's social support is often dependent on their spouses' social investment, and that men's health is therefore more dependent on marriage than women's.

Because our data contain no information on health behavior or on financial and social capital, this study cannot directly address the causes of the observed gender differences in social mortality differentials. Given that the gender difference in the educational mortality gradient is not found to be sensitive to housing situation, a variable we use as a proxy for income and wealth, we believe that the lesser dependency of material resources on education does not explain why education has a weaker impact on female longevity.

In order to have at least an idea of the role played by behavioral patterns, we looked at data from the Swiss health surveys. Since 1992, the Swiss Federal Statistical Office has conducted a survey every five years that monitors the health of the Swiss population. The results on the association between health behavior and social status have been published only for the 1997 survey (Huwiler et al. 2002), but the data needed to study that relationship are also available for the 1992 and the 2002 surveys. For both sexes and for two age groups (25-44 years and 45-69 years), we crossed a series of health behaviors (smoking, alcohol consumption, physical inactivity, and body weight) with level of educational achievement and with marital status.

In general, the observed associations are rather weak, and, apart from physical inactivity, risk behaviors appear to be more prevalent among men. With respect to physical inactivity and body weight, their associations with level of education and marital status did not differ between the sexes. There are, however, gender differences in the way smoking behavior and alcohol consumption are related to the level of education and marital status. Smoking and at-risk drinking is more closely related to marital status in women, mainly because of higher prevalence of heavy smoking in divorced women, and also because of a higher proportion of women who engage in atrisk drinking among the non-married population. The association between smoking and the level of educational achievement is higher among men, whereas at-risk drinking is more closely related to educational level in women. This higher association in women stems from an inverse educational gradient in female alcohol consumption, as women with higher education tend to drink greater quantities of alcohol, and to drink more frequently (Huwiler et al. 2002). While the higher prevalence of smoking among lower 
educated men may contribute to the sharp educational gradient in male mortality, the higher proportion of at-risk drinking women in the category of tertiary education may level out the educational gradient in female mortality. However, as all observed associations between level of education and health behavior are rather weak, the contribution of gendered lifestyles to gender differences in social mortality differentials must also be small.

\subsection{Conclusion}

Gender differences in social mortality differentials add a layer of complexity to public health policies that seek to reduce social inequality in longevity. Put differently, public health campaigns must take gender differences into account, and may have to address men and women separately, especially in contexts of important gender differences in mortality differentials. Before good policy can be designed, inequalities need to be properly measured. Our analysis has shown that a combination of different indicators gives the most complete picture of gender differences in social mortality differentials. While life expectancy is an easily interpretable indicator, it has the limitation that absolute and relative between-group differences in this measure depend on the underlying level of mortality. Age-specific mortality rate ratios refine and complete the findings based on life expectancies. They are not dependent on levels of mortality, and help to detect the age pattern of the differential. Proper measures should also take confounding factors into account. Confirming the findings of a recent study on Finland (Martikainen et al. 2005), our study has shown that gender differences in the mortality differential by marital status become substantially smaller when socio-demographic control variables, such as employment status, are taken into account. The meaning of this result is that the reasons behind the higher mortality differential by marital status in men do not lie in individuals' marital status alone, but also in its correlates. This finding is relevant for policy makers who should be aware of the causes of social differentials in mortality. The full explanation of gender differences in social mortality differentials is beyond the scope of this descriptive study. Nonetheless, our analyses indicate that, in Switzerland, gender differences in the educational mortality gradient cannot be explained by a weaker relationship between material resources and education among women. Gender differences in health behavior may be part of the reason why the educational gradient in mortality differs between the sexes, but there must be other reasons as well. Future research should address these causes in order to refine public policy that seeks to reduce social inequality in mortality. 


\section{Acknowledgments}

The authors would like to thank three anonymous reviewers for their thoughtful comments on earlier drafts of this article. This work was supported by the Swiss National Science Foundation (grant 3347CO-108806 and grant 100012-116416/1). The authors thank the Federal Statistical Office, whose support made the Swiss National Cohort and this study possible. 


\section{References}

Becker, G. (1981). A treatise on the family. Boston: Harvard University Press.

Bopp, M., Spoerri, A., Zwahlen, M., Gutzwiller, F., Paccaud, F., Braun-Fahrländer, C., Rougement, A., and Egger, M. (2009). Cohort profile: The Swiss national cohort - a longitudinal study of 6.8 million people. International Journal of Epidemiology 38(2): 379-384. doi:10.1093/ije/dyn042.

Cambois, E. and Laborde, C. (2009). A gender-specific widening in social mortality differentials in France in the prism of the changing class distribution and careers. Paper presented at IUSSP XXVI International Population Conference, Marrakech, Morocco, September 27 - October 2, 2009.

Chiang, C.L. (1984). The life table and its applications. Malabar, FL: Robert E. Krieger Publishing.

Deboosere, P., Gadeyne, S., and Van Oyen, H. (2009). The 1991-2004 evolution in life expectancy by educational level in Belgium on linked census and population register data. European Journal of Population 25(2): 175-196. doi:10.1007/ s10680-008-9167-5.

Faeh, D., Minder, C., Gutzwiller, F. and Bopp, M. (2009). Culture, risk factors and mortality : Can Switzerland add missing pieces to the European puzzle ? Journal of Epidemiology and Community Health 63(8): 639-645. doi:10.1136/ jech.2008.081042.

Goldmann, N., Korenman, S., and Weinstein, R. (1995). Marital status and long-term illness in Great Britain. Social Science and Medicine 40(12): 1717-1730.

$\mathrm{Hu}$, Y. and Goldmann, N. (1990). Mortality differentials by marital status: an international comparison. Demography 27(2): 233-250. doi:10.2307/2061451.

Huwiler, K., Bichsel, M., Junker, C., Minder, E., and Calmonte, R. (2002). Soziale Ungleichheit und Gesundheit in der Schweiz. Eine Spezialauswertung der Gesundheitsbefragung 1997. Neuenburg: Bundesamt für Statistik.

Kellerhals, J., Widmer, E., and Levy, R. (2004). Mesure et démesure du couple. Paris: Payot.

Klotz, J. and Doblhammer, G. (2008). Trends in educational mortality differentials in Austria between 1981/82 and 2001/2002: A study based on a linkage of census data and death certificates. Demographic Research 19(51): 1759-1780. doi:10.4054/DemRes.2008.19.51. 
Koskinen, S., Joutsenniemi, K., Martelin, T., and Martikainen, P. (2007). Mortality differences according to living arrangements. International Journal of Epidemiology 36(6): 1255-1264. doi:10.1093/ije/dym212.

Lerch, M., Oris, M., Wanner, P., and Forney, Y. (2010). Religious affiliation and mortality in Switzerland, 1991-2004. Population 65(2): 217-250. doi:10.3917/pope.1002.0217.

Lillard, L.A. and Panis, C.W.A. (1996). Marital status and mortality: The role of health. Demography 33(3): 313-327. doi:10.2307/2061764.

Lusyne, P., Page, H., and Lievens, J. (2001). Mortality following conjugal bereavement, Belgium 1991-96: The unexpected effect of education. Population Studies 55(3): 281-289. doi:10.1080/00324720127701.

Luy, M., Di Giulio, P., and Caselli, G. (2009). Gender-specific socioeconomic mortality differences in Italy: New insights from indirect orphanhood-based estimates. Paper presented at IUSSP XXVI International Population Conference, Marrakech, Morocco, September 27 - October 2, 2009.

Martikainen, P., Martelin, T., Nihitilä, E., Majamaa, K., and Koskinen, S. (2005). Differences in mortality by marital status in Finland from 1976 to 2000: Analyses of changes in marital status distributions, socio-demographic and household composition, and cause of death. Population Studies 59(1): 99-115. doi: $10.1080 / 0032472052000332737$.

McGehee, M. (2004). Mortality. In: Siegel, J.S. and Swanson, D.A. (eds.). The methods and materials of demography. San Diego : Elsevier Academic Press: 265-300. doi:10.1016/B978-012641955-9/50046-1.

Preston, S., Heuveline, P., and Guillot, M. (2001). Demography: Measuring and modeling population processes. Malden, MA: Blackwell Publishers.

Rau, R., Doblhammer, G., Canudas-Romo, V., and Zhen, Z. (2008). Cause-of-death contributions to education inequalities in mortality in Austria between 1981/82 and 1991/92. European Journal of Population 24(3): 265-286. doi:10.1007/ s10680-007-9145-3.

Razum, O., Zeeb, H., and Rohrmann, S. (2000). The healthy migrant effect - not merely a fallacy of inaccurate denominator figures. International Journal of Epidemiology 29(1): 191-192. doi:10.1093/ije/29.1.191.

Ross, C.E. and Wu, C.L. (1995). The links between education and health. American Sociological Review 60(5): 719-745. doi:10.2307/2096319. 
Spoerri, A., Zwahlen, M., Egger, M., and Bopp, M. (2010). The Swiss National Cohort: a unique database for national and international researchers. International Journal of Public Health 55(4): 239-242. doi:10.1007/s00038-010-0160-5.

Streuli, E. (2002). Alleinleben in der Schweiz - Entwicklung, Verbreitung, Merkmale. [PhD thesis]. Zurich: University of Zurich, Faculty of Arts.

Valkonen, T. (2002). Les inégalités sociales devant la mort. In: Caselli, G., Vallin, J., and Wunsch, G. (eds.). Démographie: analyse et synthèse. Volume 3. Paris: Editions de l'Ined: 351-372.

Vallin, J. (2002). Mortalité, sexe et genre. In: Caselli, G., Vallin, J., and Wunsch, G. (eds.). Démographie: analyse et synthèse. Volume 3. Paris: Editions de l'Ined: 319-350.

Vallin, J., Caselli, G., and Surault, P. (2002). Comportements, styles de vie et facteurs socioculturels de la mortalité. In: Caselli, G., Vallin, J., and Wunsch, G. (eds.). Démographie: analyse et synthèse. Volume 3. Paris: Editions de l'Ined: 255-305.

Wray, L.A., Alwin, D.F., and McCammon, R.J. (2005). Social status and risky health behaviors: Results from the health and retirement survey. Journals of Gerontology, Series B 60B(Special Issue II): 85-92.

Wyke, S. and Ford, G. (1992). Competing explanations for associations between marital status and health. Social Science and Medicine 34(5): 523-532. doi:10.1016/0277-9536(92)90208-8. 